\title{
Commentary: Staying out of trouble-Zone 0 frozen elephant trunk and arch debranching for type A aortic dissection
}

\author{
Roland Assi, MD, MMS, and Pavan Atluri, MD
}

\footnotetext{
From the Division of Cardiovascular Surgery, Department of Surgery, Hospital of the University of Pennsylvania, Philadelphia, Pa.

Disclosures: Authors have nothing to disclose with regard to commercial support.

Received for publication Feb 15, 2019; accepted for publication Feb 15, 2019; available ahead of print March 20, 2019.

Address for reprints: Pavan Atluri, MD, Hospital of the University of Pennsylvania, 3400 Spruce St, Philadelphia, PA 19104 (E-mail: Pavan.atluri@uphs.upenn.edu).

J Thorac Cardiovasc Surg 2020;159:48-83

$0022-5223 / \$ 36.00$

Copyright $(c) 2019$ by The American Association for Thoracic Surgery

https://doi.org/10.1016/j.jtcvs.2019.02.067
}

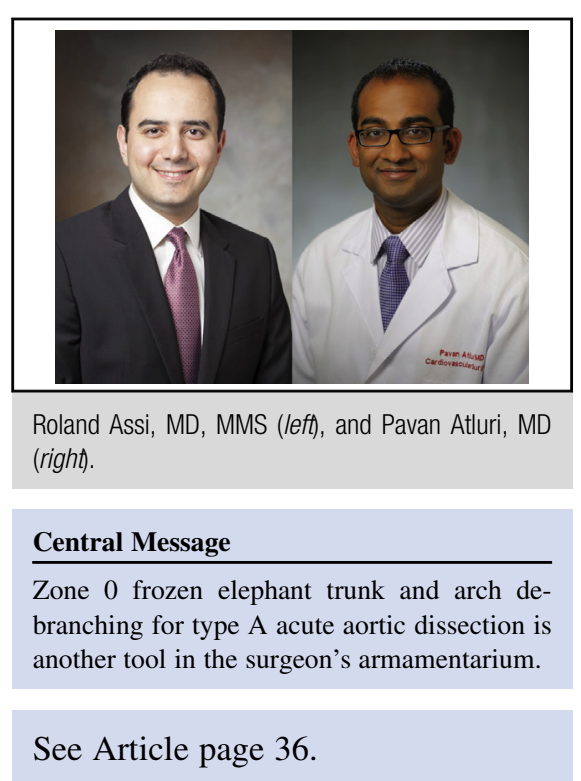

Yamamoto and colleagues ${ }^{1}$ report their experience in Japan with a novel technique for the repair of acute type A aortic dissection. Their noncomparative series includes 108 consecutive patients between 2014 and 2018 who underwent the same procedure regardless of the location of intimal tear. This operation consists of the resection of the ascending aorta from just above the sinotubular junction to just below the brachiocephalic artery, debranching of all arch vessels under moderate hypothermic circulatory arrest and antegrade cerebral perfusion, antegrade deployment of a stent graft into the proximal descending thoracic aorta all the way up to zone 0 , and replacement of the ascending aorta with a branched graft, which is then anastomosed to the proximal end of the stent graft and the arch vessels. The technique is similar to others used for open debranching in arch aneurysms, but its application for acute type A dissection is relatively novel. ${ }^{2-4}$ Technically, the stent graft used (which is not on the US market) is designed with a stentless cuff at the proximal end that makes the graft-to-graft anastomosis less challenging than a graft-to-rigid stent anastomosis, as in the classic frozen elephant trunk procedure. The technical outcomes are excellent (operative mortality, 6.5\%; stroke, $3.7 \%$; paraplegia, $0 \%$ ), and the remodeling of the aorta is full at the level of the stented portion; as expected, however, remodeling decreases significantly in proportion to the distance from the distal end of the stent graft.

Yamamoto and colleagues ${ }^{1}$ used short frozen elephant trunks, only $6 \mathrm{~cm}$ in length in $41.7 \%$ of patients, and the longest stent used was $12 \mathrm{~cm}$, with a good portion of the stent being deployed across the arch. This relatively conservative strategy is likely responsible for the absence of spinal cord injury in their series, but it may account for the few early postoperative complications: 1 case of false-lumen rupture and a $5 \%$ rate of distal extension thoracic endovascular 


\section{References}

1. Yamamoto H, Kadohama T, Yamaura G, Tanak F, Takagi D, Kiryu K, et al. Total arch repair with frozen elephant trunk using the "zone-0 arch repair" strategy for type A acute aortic dissection. J Thorac Cardiovasc Surg. 2020;159:36-45.

2. Bavaria J, Milewski RK, Baker J, Moeller P, Szeto W, Pochettino A. Classic hybrid evolving approach to distal arch aneurysms: toward the zone zero solution. $J$ Thorac Cardiovasc Surg. 2010;140(6 Suppl):S77-80; discussion S86-91.

3. Milewski RK, Szeto WY, Pochettino A, Moser GW, Moeller P, Bavaria JE. Have hybrid procedures replaced open aortic arch reconstruction in high-risk patients? A comparative study of elective open arch debranching with endovascular stent graft placement and conventional elective open total and distal aortic arch reconstruction. J Thorac Cardiovasc Surg. 2010;140:590-7.

4. Faure EM, Canaud L, Marty-Ané C, Alric P. Hybrid aortic arch repair for dissecting aneurysm. J Thorac Cardiovasc Surg. 2016;152:162-8. 